\title{
Misinformation Concerning Face Masks and the Wuhan Lab Leak
}

\author{
Colin A. Ross* \\ Institute for Psychological Trauma, 1701 Gateway, Suite 349, Richardson, TX 75080, USA \\ *Corresponding author: Colin A. Ross, Institute for Psychological Trauma, 1701 Gateway, Suite 349, Richardson, TX 75080, USA
}

Received: April 07, 2021; Accepted: April 14, 2021; Published: April 20, 2021

Leading authorities including the CDC continue to state that face masks are effective for reducing the transmission of the SARS-CoV-2 virus in public. For example, Guy, Massetti and Sauber-Schatz [1] state that, "Universal and proper masking results in substantial community benefits." Their reference in support of this statement is a report [2] that cites no data or studies showing that face masks reduce viral transmission in public. In a similar vein, Brooks and Butler [3] state with absolute confidence and authority that face masks are effective for reducing transmission of the coronavirus in public. In support of this claim they dismiss the relevance of a Danish randomized controlled trial [4] and over-ride its finding that face masks do not work in public by citing small observational reports. Leading public health authorities fail to reference the available randomized controlled trials of face masks versus no face masks for reducing viral transmission in public $[1-3,5,6]$, as previously reviewed [7-10]. The one exception [3] does cite the Danish study but dismisses it. None of the available meta-analyses of these RCTs found a single trial in which face masks provided any protective effect [11-16]. The science, then, is replicated, clear, conclusive and unambiguous: face masks do not reduce viral transmission in public. That being the case, why do all leading public health authorities state with great confidence that face masks in public are necessary? In no other area of medicine are multiple meta-analyses of RCTs over-ridden by anecdotal and uncontrolled evidence [7] - for example, hydroxychloroquine for COVID-19 has been rejected by the medical establishment and the American Medical Association because an RCT was negative and the RCT over-rode the prior anecdotal, uncontrolled reports. With face masks, the situation is reversed, and anecdotal evidence outweighs multiple negative RCTs.

The fiction that face masks are effective for reducing viral transmission in public is legislated and reinforced by governments and corporations. For example, one cannot fly on commercial airlines without a face mask. Why? Why have politicians, physicians and governments bought into this misinformation? An investigative reporter should study the money trail for face mask manufacturers, whose revenue must have increased exponentially during the pandemic. Why, before the COVID-19 pandemic, did no one wear masks inside hospitals, except in operating rooms? Why did the Surgeon General of the United States make a 180-degree turn concerning facemasks from February to April, 2020, in the absence of any new scientific evidence? In early February he stated that wearing face masks in public is unnecessary and ineffective. The World Health Organization stated that face masks in public do not reduce viral transmission well into the pandemic. What is going on here? The social control mechanisms that keep the misinformation in place are clear: these are illustrated by a recent paper that won an award for the best paper in the journal that published it in 2020 [17]. The author of that paper provided a detailed analysis of why 'anti-maskers' and 'anti-vaxxers' are suffering from groupthink. This is how the propaganda works. Anyone who questions the dogma that face masks are necessary in public is described as a conspiracy nut, anti-scientific, likely a far right-wing Trump supporter, and an enemy of the public. Much of the public has bought into the misinformation and excludes 'anti-maskers' from the ranks of the decent and civilized.

In fact, in reality, the groupthink goes in the opposite direction: the belief that face masks in public work is entirely based on groupthink. The groupthink is irrefutably disproven by science in the form of multiple RCTs. It is the 'pro-maskers' who are anti-scientific. An opinion that face masks are ineffective does not mean that the person must hold similar opinions on vaccines or social distancing. Groupthink can make a person be either pro or anti-face masks/ social distancing/vaccines - the three are often treated as a package. It is obvious that social distancing will reduce viral transmission - if no one came within 100 feet of another person, there could be no viral transmission, and no pandemic. The only point of debate is the necessary social distance required to reduce transmission by a major amount.

\section{The Wuhan Virology Lab 'Conspiracy Theory'}

Another charge of 'conspiracy theorist' is commonly levelled at individuals who believe that SARS-CoV-2 initially leaked out of the virology lab in Wuhan. Actually, this is a rational, reasonable, and scientifically grounded theory. What are the facts? You would think that blaming the pandemic on China would be palatable in the United States and the rest of the western world. Why the reluctance to do so? It's not a matter of scientific caution. Many public health officials who dismiss the Wuhan lab leak as an unfounded conspiracy theory endorse the theory that the virus jumped from bats or other animals with no supporting evidence. Robert Redfield, former head of the CDC recently stated that he thinks a Wuhan lab leak is likely the origin of the pandemic [18]: 
"I still think the most likely aetiology of this pathogen in Wuhan was from a laboratory, escaped. The other people don't believe that," said Redfield, who led the CDC under former President Donald Trump. "That's fine. Science will eventually figure it out. It's not unusual for respiratory pathogens that are being worked on in a laboratory to infect the laboratory worker."

It is not plausible to dismiss a former head of the CDC as an uninformed conspiracy nut. Notice that Redfield states that he views the Wuhan lab leak as the most likely origin of the pandemic, but he does not say that it is a proven fact. He does not attack people who have a different opinion, and he states his belief that the origin of the pandemic is a scientific question. This is the attitude that should prevail concerning the effectiveness of face masks. It is a scientific question. The science weighs overwhelmingly in favor of the conclusion that face masks do not reduce viral transmission in public. Leaks from high security labs are common and this has been known for years [19-21]. For example, there is substantial evidence that the H1N1 virus escaped from a lab in China in 1977 [20]. The SARS coronavirus leaked from the Chinese National Institute of Virology in 2004 [20]:

"In April 2004, China reported a case of SARS in a nurse who had cared for a researcher at the Chinese National Institute of Virology. While ill, the researcher had traveled twice by train from Beijing to Anhui province, where she was nursed by her mother, a physician, who fell ill and died. The nurse in turn infected five third-generation cases, causing no deaths. Subsequent investigation uncovered three unrelated laboratory infections in different researchers at the NIV. At least two primary patients had never worked with live SARS virus. Many shortcomings in biosecurity were found at the NIV, and the specific cause of the outbreak was traced to an inadequately inactivated preparation of SARS virus that was used in general (that is, not biosecure) laboratory areas, including one where the primary cases worked. It had not been tested to confirm its safety after inactivation, as it should have been."

Similarly, [20]:

"From 1963-78 the U.K. saw only four cases of smallpox (with no deaths)... that were imported by travelers from areas where smallpox was endemic. During this same period at least 80 cases and three deaths resulted from three separate escapes from two different accredited smallpox laboratories."

A leak from the Wuhan Virology lab is a plausible theory and there have been officially confirmed leaks of coronaviruses from Chinese labs. While evaluating the evidence for and against a Wuhan lab leak, and efforts to ridicule and dismiss that theory, one should bear in mind that research at the Wuhan Institute of Virology on genetic enhancement of coronaviruses to make them more virulent has been funded by the NIH and NIAID and published in a leading medical journal, Nature Medicine [22]. Authors of the paper reporting the USfunded gain of function research on coronaviruses includes authors from the University of North Carolina, Harvard Medical School and the Wuhan Institute of Virology. Commentators who express horror at the fact that the Chinese military has been conducting biological warfare experiments on viruses at the Wuhan Institute of Virology generally fail to mention that the research has been funded by the NIAID. Despite a highly effective misinformation campaign stating that face masks must be worn in public, it is a scientific fact that they don't work. Understanding how this misinformation campaign was planned, carried out and reinforced should be a priority of the medical profession and governments. The successful worldwide sale of this misinformation must have happened due to groupthink or deliberate disinformation, or a combination of the two.

\section{Concluding Thoughts}

Why do all leading public health authorities state with great confidence that face masks in public are necessary, when the science proves they are not? There are two possible explanations: 1) the statements are misinformation, or 2) they are disinformation. If scenario (1) is the case, then one must conclude that leading public health officials are incapable of reading the scientific literature and accurately evaluating and summarizing it. If scenario (2) is the case, then these officials are knowingly stating as facts what they know to be falsehoods (the falsehood that face masks work). Both these scenarios are extremely troubling. As part of either a misinformation or a disinformation campaign, the medical profession, public health officials and leading medical journals have been lying to the public - or, reporting mistaken beliefs about face masks that they honestly believe to be true. Whichever scenario is the case, the medical profession is undermining professional confidence in physicians. Instead of accusing members of the public of groupthink, maybe we should get our own house in order.

\section{References}

1. Guy GJ, Massetti GM, Sauber-Schatz E (2021) Mask mandates, on-premises dining, and COVID-19. JAMA. [crossref]

2. Honein MA, Christie A, Rose DA, Brooks JT, Meaney-Delman D, et al. (2020) CDC COVID-19 Response Team. Summary of guidance for public health strategies to address high levels of community transmission of SARS-CoV-2 and related deaths, December 2020. MMWR Morb Mortal Wkly Rep 69: 1860-1867. [crossref]

3. Brooks JT, Butler JC (2021) Effectiveness of mask wearing to control community spread of SARS-CoV-2. JAMA 325: 998-999. [crossref]

4. Bundgaard H, Bundgaard, JS, Raaschou-Pedersen DET, von Buchwald C, Todsen T, et al. (2020) Effectiveness of adding a mask recommendation to other public health measures to prevent SARS-CoV-2 infection in Danish mask wearers: A randomized controlled trial. Annals of Internal Medicine 174: 335-343. [crossref]

5. Brooks JT, Butler JC, Redfield RR (2020) Universal masking to prevent SAR-CoV-2 transmission - the time is now. JAMA. [crossref]

6. Miller BL (2020) Science denial and COVID conspiracy theories Potential neurological mechanisms and possible responses. JAMA 324: 2255-2256. [crossref]

7. Ross CA (2020) Differences in evaluation of hydroxychloroquine and face masks for SARS-CoV-2. Journal of Neurology and Neurocritical Care 3: 1-3.

8. Ross CA (2020) Thoughts on COVID-19. Journal of Neurology and Neurocritical Care 3: $1-3$.

9. Ross CA (2020) Facemasks are not effective for preventing transmission of the coronavirus. Journal of Neurology and Neurocritical Care 3: 1-2.

10. Ross CA (2020) How misinformation that facemasks are effective for reducing COVID-19 is transmitted. Journal of Neurology Neurocritical Care 3: 1-2. 
11. Chou R, Dana T, Jungbauer R, Weeks C, McDonagh MS (2020) Masks for prevention of respiratory virus infections, Including SARS-CoV-2, in health care and community settings: A living rapid review. Annals of Internal Medicine 173: 542-555. [crossref]

12. Brainard J, Jones N, Lake I, Hooper L, Hunter PR (2020) Face masks and similar barriers to prevent respiratory illness such as COVID-19: A rapid systematic review. Medrxiv.

13. Aggarwhal N, Dwarakananthan V, Gautham N, Ray A (2020) Facemasks for prevention of viral respiratory infections in community settings: A systematic review and meta-analysis. Indian Journal of Public Health 64: 192-200. [crossref]

14. Cowling BJ, Zhou Y, Ip DK, Leung GM, Aiello AE (2010) Face masks to prevent transmission of influenza virus: a systematic review. Epidemiology of Infection 138: 449-456. [crossref]

15. Xiao J, Shiu EYC, Gao H, Wong JY, Fong MW, et al. (2020) Nonpharmaceutical measures for pandemic influenza in non healthcare settings - personal protective and environmental measures. Emerging Infectious Diseases 26: 967-975.

16. Pezzolo E, Cazzaniga S, Gallus S, et al. (2020) Evidence from randomized controlled trials on the surgical masks' effect on the spread of respiratory infections in the community. Annals of Internal Medicine.
17. Forsyth DR (2020) Group-level resistance to health mandates during the COVID-19 pandemic: A groupthink approach. Group Dynamics. Theory, Research and Practice 24: $139-152$.

18. Redfield R (2021) Interview: https://news.yahoo.com/former-cdc-director-redfieldsays-130733234.html.

19. Wertheim JO (2010) The re-emergence of H1N1 influenza virus in 1977: A cautionary tale for estimating divergence times using biologically unrealistic sampling dates. PLOS One 5: 1-4. [crossref]

20. Furmanski M (2015) A brief, terrifying history of viruses escaping from labs: 70s Chinese pandemic was a lab mistake. National Post https: //nationalpost.com/news/ a-brief-terrifying-history-of-viruses-escaping-from-labs-70s-chinese-pandemicwas-a-lab-mistake.

21. Piper K (2019) How deadly pathogens have escaped the lab-over and over again VOX https://www.vox.com/future-perfect/2019/3/20/18260669/deadly-pathogensescape-lab-smallpox-bird-flu.

22. Menachery VD, Yount BL, Debbink K, Agnihothram S, Gralinksi LE, et al. (2015) SARS-like cluster of circulating bat coronaviruses shows potential for human emergence. Nature Medicine 21: 1508-1513.

\section{Citation:}

Ross CA (2021) Misinformation Concerning Face Masks and the Wuhan Lab Leak. J Neurol Neurocrit Care Volume 4(1): 1-3. 